\title{
Diversity and path coefficient analysis of Southern African maize hybrids
}

Lorraine Mhoswa ${ }^{1}$, John Derera ${ }^{1}$, Fikile N.P. Qwabe ${ }^{2}$, and Tatenda R. Musimwa ${ }^{1 *}$

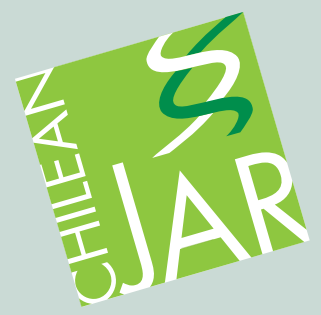

\section{ABSTRACT}

Detailed knowledge on genetic diversity among germplasm is important for hybrid maize (Zea mays L.) breeding. The objective of the study was to determine genetic diversity in widely grown hybrids in Southern Africa, and compare effectiveness of phenotypic analysis models for determining genetic distances between hybrids. Fifty hybrids were evaluated at one site with two replicates. The experiment was a randomized complete block design. Phenotypic and genotypic data were analyzed using SAS and Power Marker respectively. There was significant $(\mathrm{p}<0.01)$ variation and diversity among hybrid brands but small within brand clusters. Polymorphic Information Content (PIC) ranged from 0.07 to 0.38 with an average of 0.34 and genetic distance ranged from 0.08 to 0.50 with an average of 0.43 . SAH23 and SAH21 (0.48) and SAH33 and SAH3 (0.47) were the most distantly related hybrids. Both single nucleotide polymorphism (SNP) markers and phenotypic data models were effective for discriminating genotypes according to genetic distance. SNP markers revealed nine clusters of hybrids. The 12-trait phenotypic analysis model, revealed eight clusters at $85 \%$, while the five-trait model revealed six clusters. Path analysis revealed significant direct and indirect effects of secondary traits on yield. Plant height and ear height were negatively correlated with grain yield meaning shorter hybrids gave high yield. Ear weight, days to anthesis, and number of ears had highest positive direct effects on yield. These traits can provide good selection index for high yielding maize hybrids. Results confirmed that diversity of hybrids is small within brands and also confirm that phenotypic trait models are effective for discriminating hybrids.

Key words: Genetic diversity, grain yield, phenotypic traits, SNP markers, Zea mays.

${ }^{1}$ University of KwaZulu-Natal, School of Agricultural, Earth and Environmental Science, Private Bag X01, Scottsville, Pietermaritzburg 3209, South Africa. ${ }^{*}$ Corresponding author (musimwatate@ gmail.com). ${ }^{2}$ KwaZulu-Natal Department of Agriculture and Rural Development, Private Bag X9059, Pietermaritzburg, 3209, South Africa.

Received: 18 August 2015.

Accepted: 24 December 2015.

doi:10.4067/S0718-58392016000200002

\section{INTRODUCTION}

Maize (Zea mays L.) is the principal crop of Southern Africa because it is a staple food. However, adequate production of maize is hampered by poor yields. There is need therefore to improve yield of hybrids through breeding. Information on genetic diversity (GD) in maize is of fundamental importance in crop improvement (Choukan, 2011). This information helps in classifying germplasm in appropriate heterotic groups for future breeding programs because genetically divergent genotypes are known to have high hybrid vigor (Dandolin et al., 2008). Knowledge on the GD is important to plant breeders so that they know the extent of already existing genetic variability in the material and improve on them (Cholastova et al., 2011). There is much emphasis on the use of diverse genotypes because they contribute to high yields. Hallauer and Miranda (1988) reported that divergent population improvements usually targets to increase yield and heterosis.

Diversity can be estimated by using a number of methods and these include pedigree data and molecular markers (Semagn et al., 2012). Various types of molecular markers can be used to estimate GD and these include restriction fragment length polymorphism (RFLP), random amplified polymorphic DNA (RAPD), amplified fragment length polymorphism (AFLP), simple sequence repeats (SSR), and single nucleotide polymorphism (SNP) markers. Nowadays there is a shift towards the use of SNP markers, because of their low cost per data point, high genomic abundance, co-dominance, potential for high throughput analysis and lower genotyping error rates (Foster et al., 2010; Semagn et al., 2012). Semagn et al. (2012) reported that SNP markers have emerged as a powerful tool for many genetic applications in genetic diversity studies and marker assisted breeding. Lu et al. (2011) compared the GD using SNP markers between tropical and temperate lines and found out that tropical germplasm had substantial higher GD (0.238-0.548) than temperate (0.224-0.473). Semagn et al. (2012) evaluated genetic distance for elite lines using SNP markers and results showed that $94 \%$ of the pair lines fell between $(0.300$ 0.400). Therefore, in this study SNP markers were used. Diversity can be also studied using phenotypic traits. Hepziba et al. (2013) studied diversity using phenotypic traits and reported that phenotypic traits were very effective as they clustered 70 maize inbred lines into 10 clusters.

Cheres et al. (2000) reported that estimation of GD with the use of phenotypic characteristics gives less accurate results. This was in contrast with Bertan et al. (2007), who reported that phenotypic traits were very effective in estimating genetic distance. However, 
Leal et al. (2010) reported that molecular markers have proved to have advantages over other methods because they show genetic differences on a more detailed level without interferences from environmental factors and they involve techniques that provide fast results detailing genetic diversity. Therefore, one of the aim of this study was to evaluate the effectiveness of using both molecular markers and phenotypic traits in determining GD.

Genetic distance can be estimated using Mahalanobis $\left(D^{2}\right)$ or Euclidean distance (Bertan et al., 2007). Clustering method is then used to separate the observations into many subgroups in order to obtain homogeneity within and between these groups (Bertan et al., 2007). Hierarchical methods are used to group genotypes thereby forming a dendrogram without concern for the number of groups formed. Different clustering methods are used depending on the procedure that is most suitable for the data set. Data obtained from the clusters can be used to make conclusions on the potential heterotic groups and new heterotic patterns, which improve yield in maize hybrids. Hence, in this study the Euclidean distance was used to estimate genetic distance.

The objectives of this study were to determine genetic diversity in widely grown Southern African maize hybrids and determine the relationship between grain yield and secondary traits.

\section{MATERIALS AND METHODS}

\section{Germplasm and genotyping}

Fifty (50) commercial maize hybrids were selected for the genetic diversity study and were coded for convenience, as SAH1 to SAH50. The hybrids were drawn from nine brands that are available on the market in Southern Africa.

Single nucleotide polymorphism (SNP) markers were used for genotyping. The 50 maize hybrids were grown in a tunnel in four pots each. Leaf tissues were harvested from each of the four plants at the $4 \mathrm{wk}$ stage. Two leaf discs (punches or equivalent) approximately $20 \mathrm{~mm}$ in diameter were harvested from each plant and were put in the specific well positions. A sheet of Air Pore Tape (Qiagen, Germantown, Maryland, USA) was put on top of the block to seal. The block was then placed inside a plastic bag together with $50 \mathrm{~g}$ silica gel and the material was then dried for $24 \mathrm{~h}$. The indicator gel was used to confirm if it was dehydrated (blue when it is dehydrated or pink when hydrated). The samples were airfreighted to DNA landmarks lab in Canada for analysis.

DNA was extracted following Sarkosyl Nitrogen method at the DNA landmarks (Hasan et al., 2008). Genotypic data was analyzed using Power Marker (version 3.25) statistical package (Liu and Muse, 2005). Polymorphic information content (PIC) value of an $l$-allele locus can be calculated using the following formula:

$$
\mathbf{P I C}=1-\sum_{i=1}^{l} P_{i}^{2}-\sum_{i=1}^{l-1} \sum_{j=i+1}^{l} 2 P_{i}^{2} P_{j}^{2}
$$

where $\mathrm{P}_{\mathrm{i}}$ and $\mathrm{P}_{\mathrm{j}}$ are the population frequency for the $i^{\text {th }}$ and $j^{\text {th }}$ allele. PIC values give an estimate of the discriminatory power of a marker by taking into account not only the number of alleles at the locus but also the relative frequencies of these alleles.

Allelic diversity was calculated as follows (Botstein et al., 1980):

$$
\operatorname{Div}=1-\sum_{u=1}^{k} \tilde{p}_{u}^{2}
$$

\section{Field trial design and management}

The hybrids were evaluated at Ukulinga Research Station $\left(29.67^{\circ} \mathrm{S}, 30.41^{\circ} \mathrm{E}\right)$ during the $2012-2013$ season. The trial was planted on 26 November 2012. The experiment was laid out as a randomized complete block design with three replicates. Each plot comprised of four rows of $5 \mathrm{~m}, 0.75$ $\mathrm{m}$ between rows and $0.30 \mathrm{~m}$ within rows. The experiment was rain fed. Fertilizer was applied as basal at planting in the form of a compound (NPK) 2:3:4 at $250 \mathrm{~kg} \mathrm{ha}^{-1}$ (56 kg N ha-1, $83 \mathrm{~kg} \mathrm{P} \mathrm{ha}^{-1}$, and $111 \mathrm{~kg} \mathrm{~K} \mathrm{ha}^{-1}$ ). Nitrogen fertilizer was applied at 4 wk after crop emergence in the form of lime ammonium nitrate $(28 \% \mathrm{~N})$ at $250 \mathrm{~kg} \mathrm{ha}^{-1}$. The herbicides paraquat, S-metolachlor, bentazon, and 2,4D were applied to control weeds. This was augmented by hand weeding to keep the fields relatively clean of weeds throughout the season. Insecticide granules were applied in the maize leaf whorls for stalk borer control. An insecticide, lambda cyhalothrin (Karate; Syngenta, Basel, Switzerland) was applied to control cutworm at planting and seedling emergence.

\section{Data collection and data analysis}

The maize traits were measured following standard protocols used at International Maize and Wheat Improvement Center (CIMMYT, Magorokosho et al., 2009): Grain yield, plant height $(\mathrm{cm})$, ear height $(\mathrm{cm})$, days to anthesis, stem lodging, grain moisture, ear prolificacy, number of plants, ear weight $(\mathrm{g})$, and days to silking, tillering, and silking.

The dendrogram for SNPs markers was constructed using Power Marker software (version 3.25; Liu and Muse, 2005). Phenotypic dendrograms were constructed using GENSTAT (version $14^{\text {th }}$ edition; VSN International, Hemel Hempstead, UK). General ANOVA was performed using SAS 9.3 version (SAS Institute, 2011). Hybrid data were analyzed as randomized complete block design using the following model:

$$
\mathrm{Y}_{\mathrm{ij}}=\mu+\mathrm{B}_{\mathrm{i}}+\mathrm{T}_{\mathrm{j}}+\mathrm{E}_{\mathrm{ij}}
$$

where, $Y_{i j}$ is observed response, $\mu$ is grand mean, $B_{i}$ is effect of the $\mathrm{i}^{\text {th }}$ block, $i=1 . \ldots 3, T_{j}$ is effect of the $\mathrm{j}^{\text {th }}$ treatment, $j$ is $1 \ldots .50$, and $E_{i j}$ is random experimental error.

Path analysis and correlation analysis were performed in SAS version 9.3 (Scott and Milliken, 1993). 


\section{RESULTS}

\section{Molecular marker characterization and genetic distance among hybrids}

There was considerable variation between hybrids. The characteristics of 94 SNP markers analyzed are shown in Figures 1 and 2. Only three markers (PZB02480_1, PZB02033_2, and PZB00175_6) had a low call rate of $0 \%, 5 \%$, and $85 \%$, respectively, so they were not included in data analysis. The PIC ranged from 0.07 (PZA03728_1) to 0.38 (PZA01735 and PZA01755_1) with an average of 0.34 . Approximately $65 \%$ of the markers used (61 out of 94) had PIC value exceeding 0.30 demonstrating the good discriminatory power of the markers suggesting that

Figure 1. Distribution of the 91 SNP markers for Polymorphic Information Content.

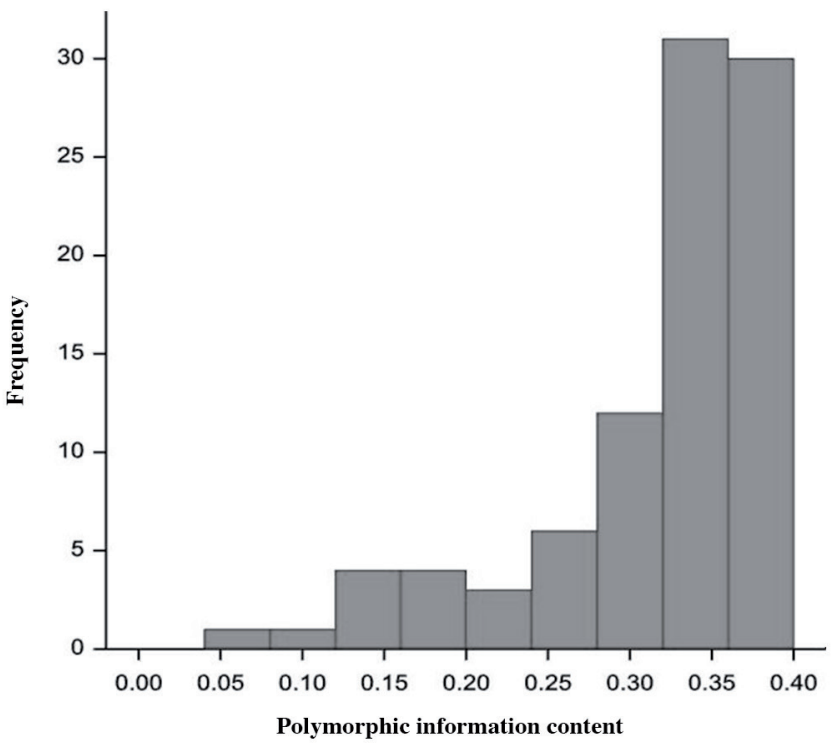

Figure 2. Distribution of the 91 SNP markers for diversity.

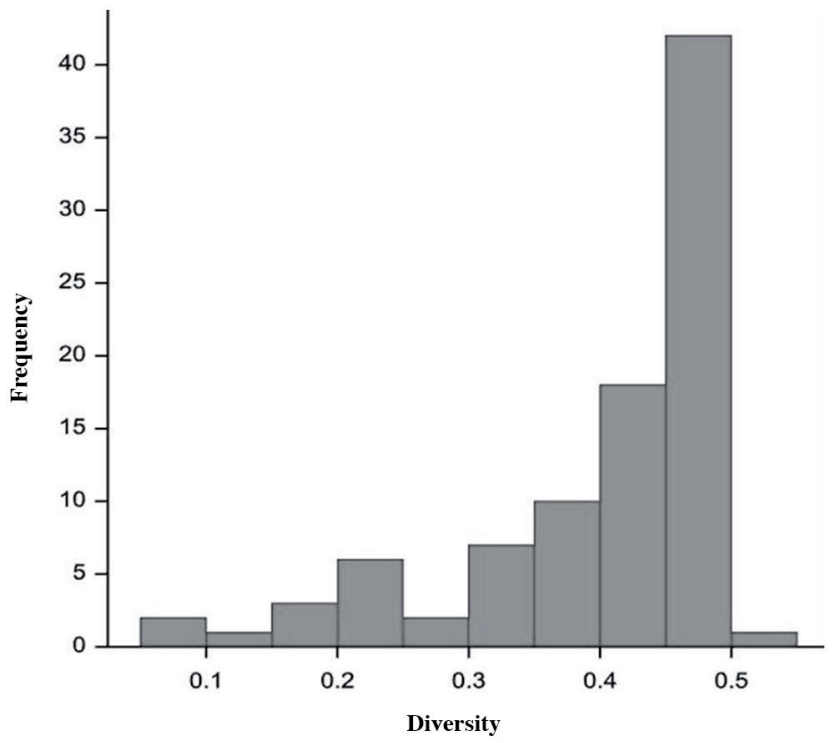

considerable variation between hybrids is detectable with SNP markers. SNP diversity data ranged from 0.08 to 0.50 with an average of 0.43 , however the vast majority $(85.7 \%$ ) fell between 0.30 and 0.50 (Figure 2).

Genetic distance among hybrids, there was a large diversity among the hybrids. Using SNP markers the highest genetic distance between the hybrids was 0.48 and the lowest was 0.01 . The highest genetic distance above 0.40 was found between SAH23 and SAH21, SAH33 and SAH1, SAH32 and SAH18, and SAH33 and SAH23. Conversely, the lowest genetic distance (0.01) was found between SAH6 and SAH24, SAH34 and SAH25, SAH34 and SAH37 and SAH37 and SAH25.

Using phenotypic traits, the highest genetic distance was found between SAH43 and SAH1 and SAH33 and SAH1. Conversely, the lowest genetic distance was found between SAH31 and SAH40, SAH5 and SAH42 and SAH41 and SAH38. Genetic distance summary for 50 hybrids measured against a tropical hybrid SAH33 are shown in Figure 3. Almost all hybrids fell between 0.25 and 0.48 with an exception of one hybrid that had genetic distance which was lower than 0.1 .

\section{Cluster analysis of hybrids based on molecular markers}

SNP markers were effective for discriminating the hybrids into different clusters (Figure 4). The genotypes are grouped in two major clusters I and II, whereby cluster II is the largest cluster and cluster I has two hybrids only. Cluster II is further divided into five clusters (A, B, C, D, and E) in which cluster $\mathrm{B}$ is the largest with 30 hybrids followed by cluster $\mathrm{C}$ with 11 hybrids, cluster D with four hybrids, cluster $\mathrm{E}$ with four hybrids and cluster A with 1 hybrid. Cluster B was further divided into three sub-clusters $\left(\mathrm{B}_{1}, \mathrm{~B}_{2}\right.$, and $\left.\mathrm{B}_{3}\right)$ and cluster $\mathrm{C}$ was divided into two sub-clusters $\left(\mathrm{C}_{1}\right.$ and $\left.\mathrm{C}_{2}\right)$.

Figure 3. Genetic distance data summary of $\mathbf{5 0}$ hybrids using phenotypic traits measured against a tropical hybrid (SAH33).

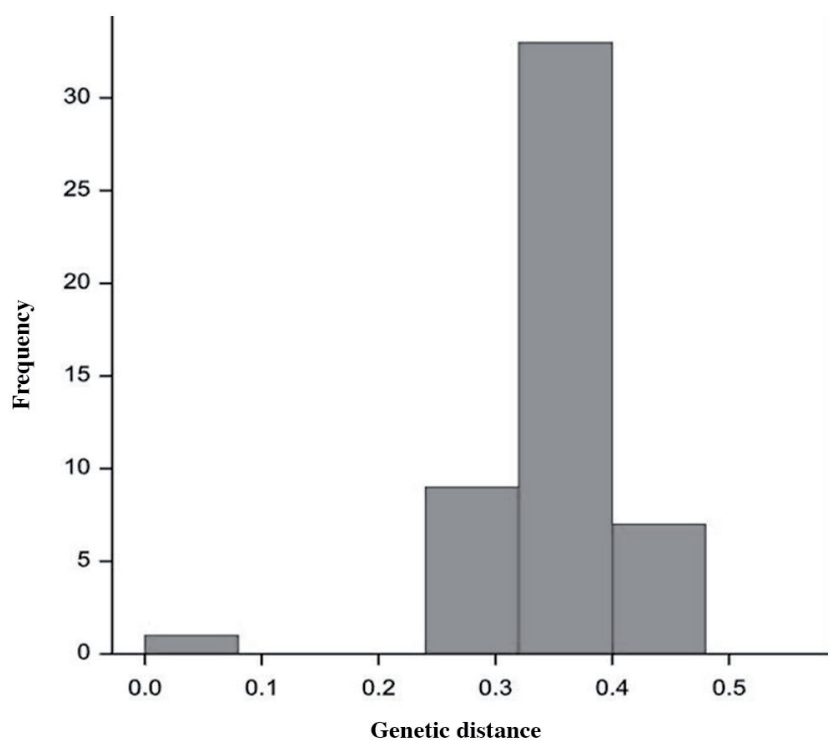


Figure 4. Dendrogram of 50 maize hybrids based on 91 SNP molecular markers using Euclidean distance.

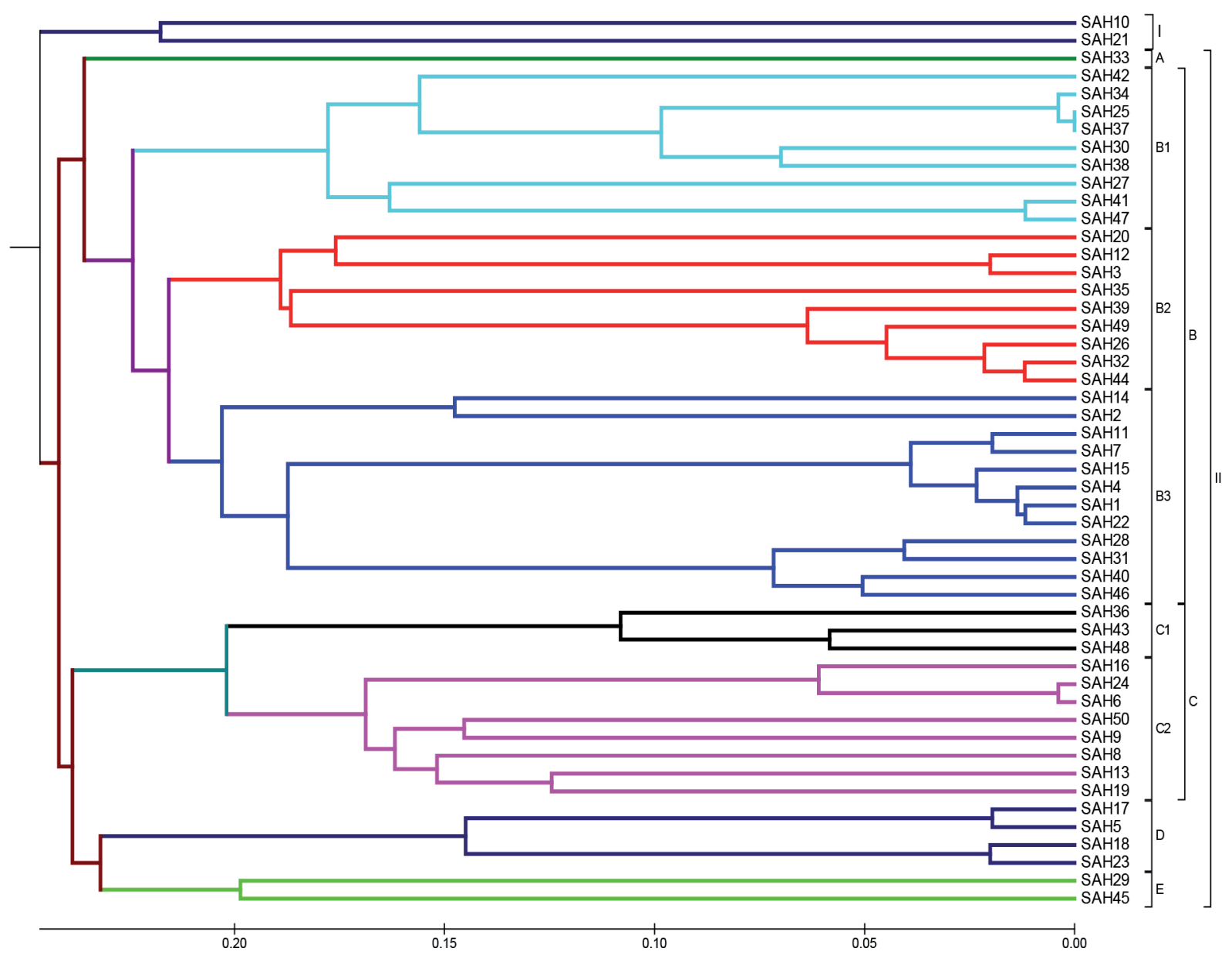

\section{Cluster analysis based on 12 phenotypic traits model}

Phenotypic data were effective for discriminating the hybrids into different clusters (Figure 5). The dendrogram of 50 maize hybrids was based on the following 12 traits plant height, ear height, number of plants, number of ears, ear weight, grain weight, ear prolificacy, stem lodging, root lodging, tillers, pollen date and silking date. There are two major clusters I and II at a 0.6 cut-off point; however four clusters (A, B, C, and D) are shown at a cut-off point of 0.75 . Furthermore, at 0.85 cut-off point cluster $\mathrm{B}$ is sub-divided into $B_{1}$ and $B_{2}$, cluster $C$ is sub-divided into $C_{1}, C_{2}$ and $C_{3}$ and lastly cluster $\mathrm{D}$ is sub-divided into $\mathrm{D}_{1}$ and $\mathrm{D}_{2}$.

\section{Cluster analysis based on five phenotypic traits model}

Phenotypic data using fewer traits (five) was less effective for discriminating the hybrids into different clusters compared when using more phenotypic data (Figure 6). The dendrogram of 50 maize hybrids was constructed using stem lodging, tillering, ear prolificacy, grain moisture, and grain yield. There are two major clusters I and II at 0.60 cut-off point; however four clusters $\mathrm{A}, \mathrm{B}, \mathrm{C}$, and $\mathrm{D}$ are shown at a cut-off point of 0.75 . Furthermore, at 0.85 cut-off point cluster $\mathrm{A}$ is sub-divided into $\mathrm{A}_{1}$, cluster $\mathrm{B}$ in to $\mathrm{B}_{1}$, cluster $\mathrm{C}$ into $C_{1}$ and $C_{2}$, and cluster $D$ into $D_{1}$ and $D_{2}$.

\section{Relationship between phenotypic traits}

Differences were observed in correlation coefficients in terms of magnitude and direction. There was positive correlation among phenotypic traits though most were nonsignificant (Table 1). Only ear prolificacy and ear weight showed positive correlation with grain yield (more than 0.50). However, plant height, ear height, days to anthesis, and days to silking showed negative correlation with yield. Positive values of correlation of coefficient was found among almost all other traits with a few exceptions of grain moisture and number of plants, tillering and ear prolificacy and tillering and ear weight. Plant height correlated significantly ( $p$ $<0.01$ ) and positively with ear height, days to anthesis and days to silking (Table 1). Days to anthesis correlated significantly ( $\mathrm{p}<0.01$ ) with days to silking, days to silking 
Figure 5. Dendrogram of 50 maize hybrids based on 12 phenotypic traits model using Euclidean distance.

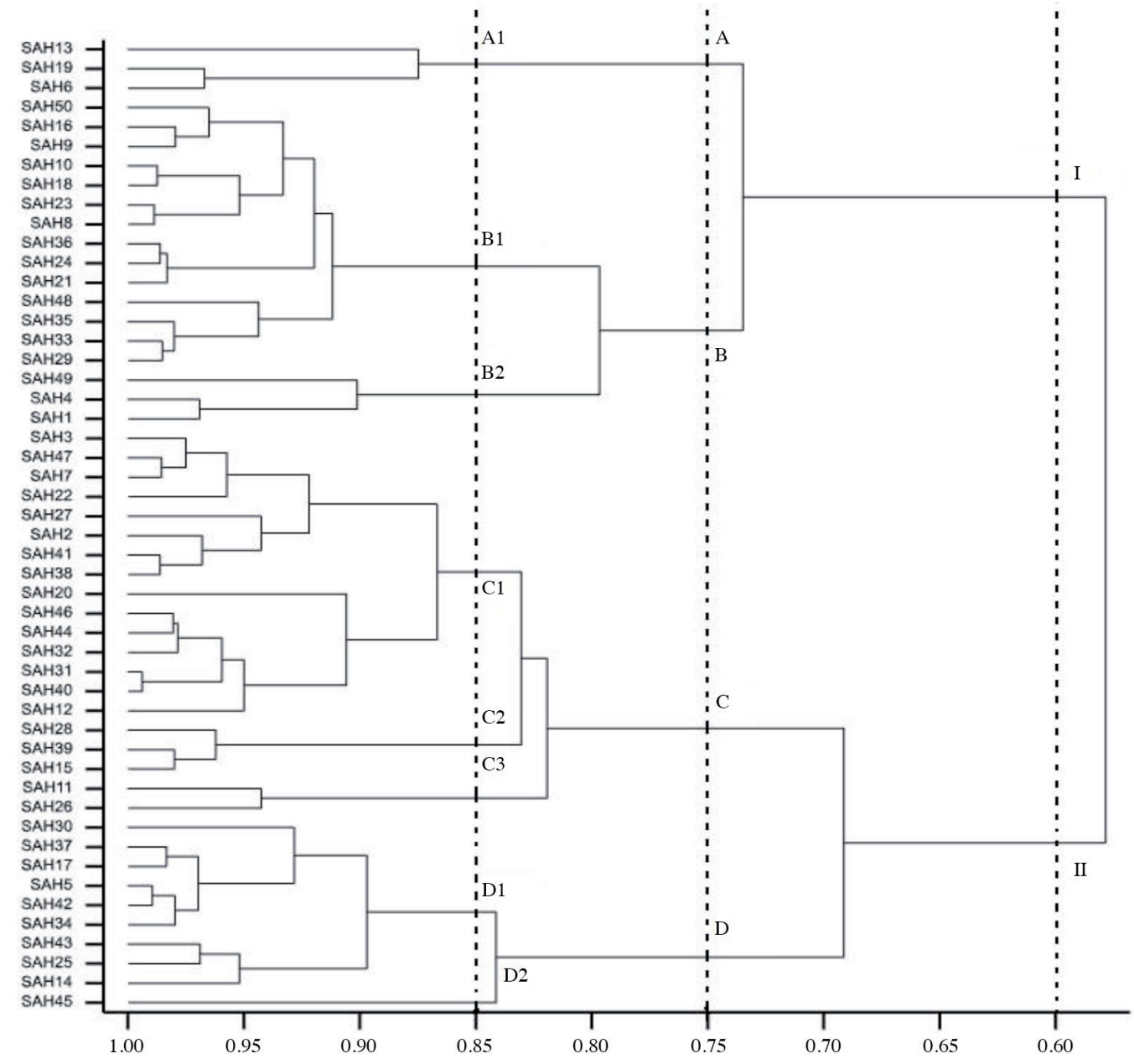

and grain moisture, days to anthesis and ear height. Ear prolificacy correlated significantly $(\mathrm{p}<0.05)$ and negatively with number of plants.

\section{Path analysis}

Direct effects of secondary traits were more influential on yield compared to indirect effects. Regression data showing the level of significance for direct effects is presented in Table 2. Ear weight and grain moisture were the only traits that were highly significant $(\mathrm{p}<0.0001)$ for direct effects on yield. The dependent variable grain yield is mostly influenced by the direct effects on an independent variable and its indirect effects via other yield components. Ear weight exhibited the highest direct and positive effects on yield followed by days to anthesis, number of ears and plant height (Table 3). However, grain moisture displayed the highest negative direct effects on grain yield followed by days to silking, ear prolificacy, and number of plants. Number of ears showed indirect positive effects on grain yield through ear weight followed by ear prolificacy via ear weight, grain moisture through ear weight and number of plants via ear weight. Highest indirect negative effects on grain yield were exhibited by ear weight through grain moisture, followed by days to anthesis via days to silking, number of ears through prolificacy and ear height via grain moisture.

\section{DISCUSSION}

\section{Polymorphism of the SNP markers}

Of the 94 SNPs identified 91 were used with only three being dropped because they had a low call rate $(<90 \%)$. PIC had the highest value of 0.38 and these results are in line with Hao et al. (2011), who reported highest value of PIC of 0.375 using 1536 SNP markers on 95 maize inbred lines. These results are in accordance with Yang et al. (2011), who reported the highest value of PIC of 0.38 using 884 SNP markers. The average PIC value in this study was higher, 0.34 compared to PIC of 0.239 reported by $\mathrm{Hao}$ et al. (2011) and $\mathrm{Lu}$ et al. (2009), who reported average PIC value of 0.25 using 1034 SNP markers on 770 maize lines. The efficacy of SNP markers used in the study can be explained by the fact that they were carefully selected at a ratio of 10 per chromosome and their uniform coverage of the genome. Therefore, the diversity data generated can be considered reliable. This set of SNP markers will be recommended for future studies for genotyping maize inbred lines. 
Figure 6. Dendrogram of $\mathbf{5 0}$ maize hybrids based on five phenotypic traits model using Euclidean distance.

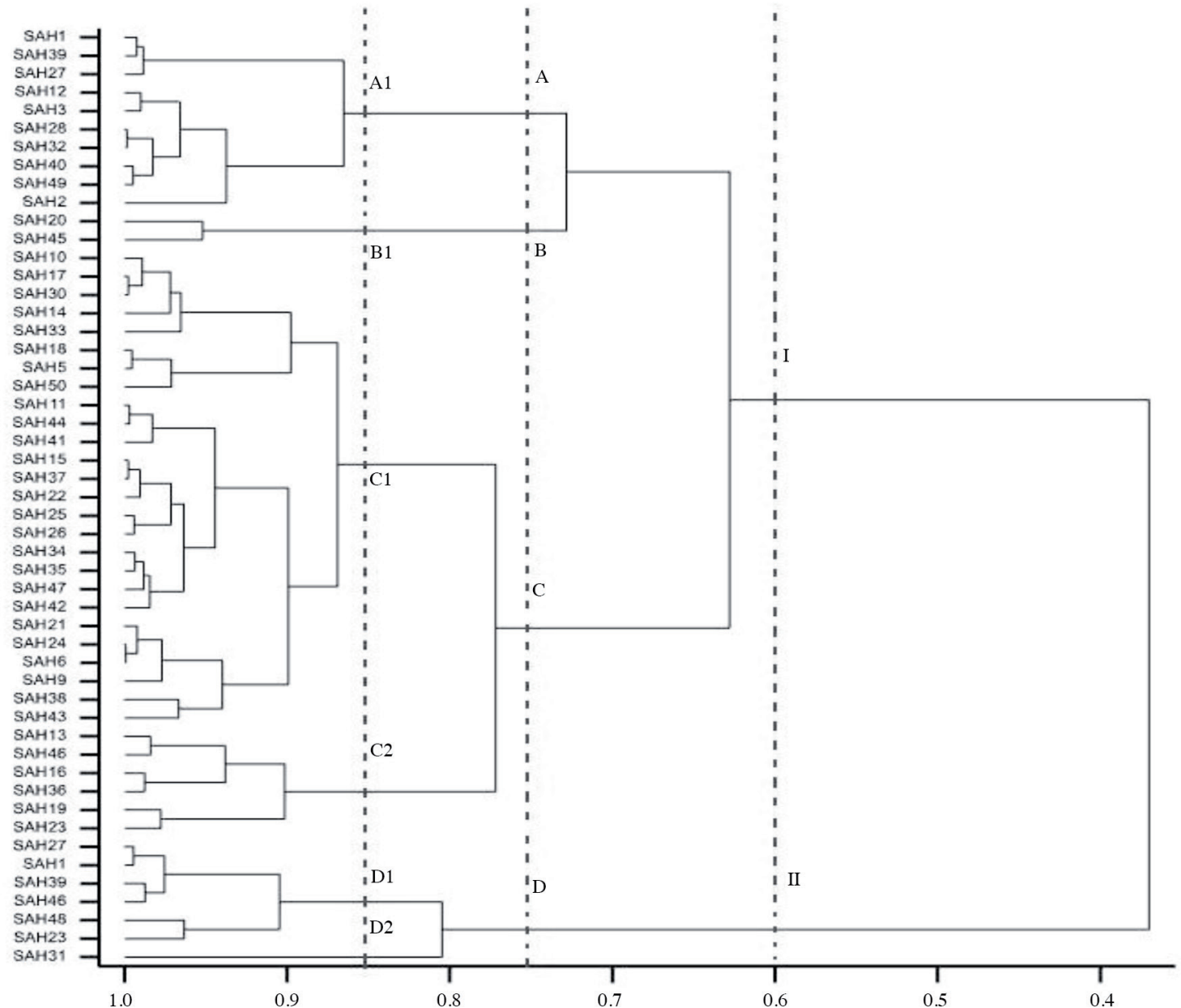

\section{Genetic distance}

There was genetic variation between the maize hybrids. SAH 23 and SAH21 (0.48) and SAH33 and SAH3 (0.47) were the most distantly related hybrids. This indicates that these hybrids belong to different genetic clusters. Hence, they have the potential to produce superior hybrids when crossed. This is in line with Hallauer and Miranda (1988), who asserts that the genetic divergence of parental varieties determines the manifestation of heterosis, and that the heterotic patterns are determined by the genetic divergence of two parental varieties. The lowest genetic distance were found between SAH6 and SAH24 (0.01), SAH34 and SAH25 (0.01), SAH34 and SAH37 (0.01) and SAH37 and

Table 1. Relationship among phenotypic traits of $\mathbf{4 6}$ maize hybrids at Ukulinga.

\begin{tabular}{|c|c|c|c|c|c|c|c|c|c|c|c|}
\hline & GYG & PH & EH & NP & EW & GM & SL & $\mathrm{TL}$ & EPP & $\mathrm{DA}$ & DS \\
\hline GYG & - & & & & & & & & & & \\
\hline PH & -0.08 & - & & & & & & & & & \\
\hline EH & $-0.06^{*}$ & $0.68^{* *}$ & - & & & & & & & & \\
\hline NP & 0.26 & 0.24 & 0.09 & - & & & & & & & \\
\hline EW & 0.64 & 0.20 & 0.09 & $0.64^{* *}$ & - & & & & & & \\
\hline GM & 0.30 & 0.22 & $0.53^{*}$ & 0.17 & -0.06 & - & & & & & \\
\hline SL & $0.11^{*}$ & 0.10 & 0.27 & 0.17 & 0.10 & $0.32^{*}$ & - & & & & \\
\hline $\mathrm{TL}$ & $0.19^{* *}$ & 0.22 & 0.23 & -0.10 & -0.11 & -0.10 & -0.26 & - & & & \\
\hline EPP & 0.51 & 0.02 & 0.18 & 0.21 & 0.08 & 0.20 & 0.29 & 0.14 & - & & \\
\hline DA & $-0.08^{*}$ & $0.41^{*}$ & $0.63^{* *}$ & 0.20 & 0.09 & $0.56^{* *}$ & $0.34^{*}$ & 0.13 & $0.33^{*}$ & - & \\
\hline DS & $-0.05^{*}$ & $0.38^{*}$ & $0.61^{* *}$ & 0.24 & 0.10 & $0.55^{* *}$ & $0.35^{*}$ & 0.14 & $0.36^{*}$ & $0.99^{* *}$ & - \\
\hline
\end{tabular}

GYG: Grain yield, PH: plant height, EH: ear height, NP: number of plants, EW: ear weight, GM: grain moisture, SL: stem lodging, TL: tillering, EPP: ear prolificacy, DA: days to anthesis, DS: days to silking. 
Table 2. Regression data showing levels of significance for direct effects of secondary traits on yield in maize hybrids.

\begin{tabular}{lcccc}
\hline Trait & $\begin{array}{c}\text { Parameter } \\
\text { estimate }\end{array}$ & $\begin{array}{c}\text { Standard } \\
\text { error }\end{array}$ & t-value & P-value \\
\hline Plant height & 0.0042 & 0.0365 & 0.11 & 0.9100 \\
Ear height & 0.0095 & 0.0483 & 0.20 & 0.8450 \\
Number of plants & -0.0476 & 0.0295 & -1.61 & 0.1162 \\
Number of ears & 0.0410 & 0.0968 & 0.42 & 0.6750 \\
Ear weight & 1.1551 & 0.0430 & 26.88 & $<0.0001^{* * *}$ \\
Grain moisture & -0.2629 & 0.0397 & -6.62 & $<0.0001^{* * *}$ \\
Days to anthesis & 0.11619 & 0.3074 & 0.38 & 0.7079 \\
Days to silking & -0.1334 & 0.3040 & -0.44 & 0.6637 \\
Ear prolificacy & 0.0281 & 0.0563 & 0.50 & 0.6210 \\
Stem lodging & -0.0487 & 0.0320 & -1.52 & 0.1368 \\
Tillering & -0.0159 & 0.0326 & -0.49 & 0.6291 \\
* *** and $^{* * * *}$ Significant at $0.05,0.01$, and 0.001 probability levels, respectively.
\end{tabular}

SAH25 (0.01) indicating that they were most closely related to each other. Therefore, they belong to the same heterotic group and have less potential to produce superior hybrids when crossed. This is because crossing germplasm that is closely related results in inbreeding depression rather than hybrid vigor. The minimum genetic distance from the study confirmed the ability of SNP markers to distinguish closely related hybrids.

\section{Cluster analysis based on molecular data and phenotypic data}

SNP markers. The SNP markers were effective for discriminating maize hybrids according to genetic backgrounds and brands. Hybrids that are clustered in subcluster $\mathrm{B}_{1} \mathrm{SAH} 3$ and SAH12 are derived from the same brand. The same applies for SAH25, SAH34, and SAH37. Hybrid lines in sub-cluster $\mathrm{B}_{2} \mathrm{SAH} 12$, and SAH3 are also from the same brand. In addition, SAH6 and SAH24 in subcluster $\mathrm{C}_{2}$ have the same background. SAH5 and SAH17 in cluster D are derived from the same brand. Similar results have been reported in studies conducted by Yan et al. (2010), who reported seven clusters obtained by using 1362 SNP markers. Schaefer and Bernardo (2013) reported the effectiveness of SNP markers as they managed to group 284 maize inbreds into five clusters. Yang et al. (2011) reported that the same clusters were observed by using both SSR and SNP markers.

Cluster analysis based on phenotypic traits. Phenotypic trait models were effective in discriminating maize hybrids. Most of the hybrids in cluster A were non-prolific, had low ear placement, same number of plants and early maturing. SAH13 was then found alone because it had 25\% stem lodging and $11 \%$ root lodging. This can be due to the fact that SAH13 is not adapted to the South African environment. It is a tropical hybrid. Hybrids in cluster B had medium plant height and medium ear placement. Most of the hybrids had the highest number of plants, moderate prolific and late maturing. Three hybrids SAH1, SAH4, and SAH49 were in sub-cluster $B_{2}$ because they had the highest number of ears compared to the rest of the hybrids. Further, hybrids in cluster $\mathrm{C}$ were taller, high prolific, high ear placement and moderate number of plants. Most hybrids in cluster $\mathrm{C}$ had high stem lodged plants. Furthermore, hybrids in cluster $\mathrm{C}_{2}$ had the same number of plants also the same number of plants that were prolific. They also had higher number of plants with stem lodging compared to the other clusters. Hybrids in cluster $\mathrm{C}_{3}$ exhibited very high numbers of plants, number of ears, prolific and they had no plants with stem lodging and root lodging. These results are also supported by Shahrokhi and Khavarikhorasani (2013), who reported on the effectiveness of phenotypic traits as they grouped 28 maize hybrids into four clusters. Furthermore, Karanja et al. (2009) reported that both phenotypic traits and SSR markers were effective in clustering inbred lines. Pedigree analysis placed 119 inbred maize lines into eight and SSR markers

Table 3. Direct (underlined and bold) and indirect effects of different traits in 46 maize hybrids at Ukulinga.

\begin{tabular}{|c|c|c|c|c|c|c|c|c|c|c|c|c|}
\hline $\begin{array}{c}\text { Grain } \\
\text { yield } \\
\text { component }\end{array}$ & $\mathrm{PH}$ & $\mathrm{EH}$ & NP & $\mathrm{NE}$ & EW & GM & EPP & DA & DS & SL & TL & $\begin{array}{l}\text { Total } \\
\text { correlation } \\
\text { to grain } \\
\text { yield }\end{array}$ \\
\hline $\mathrm{PH}$ & 0.00 & $\underline{0.01}$ & -0.01 & 0.00 & -0.06 & -0.01 & 0.00 & 0.05 & -0.05 & 0.00 & 0.00 & -0.08 \\
\hline EH & 0.00 & $\underline{0.01}$ & -0.01 & 0.01 & 0.07 & -0.10 & -0.02 & 0.07 & -0.08 & -0.01 & 0.00 & -0.06 \\
\hline NP & 0.00 & 0.00 & $\underline{-0.05}$ & 0.01 & 0.28 & -0.03 & -0.01 & 0.02 & -0.02 & 0.01 & 0.00 & 0.20 \\
\hline $\mathrm{NE}$ & 0.00 & 0.00 & -0.01 & $\underline{0.04}$ & 0.70 & -0.09 & -0.10 & 0.05 & -0.06 & -0.01 & 0.00 & 0.52 \\
\hline EW & 0.00 & 0.00 & -0.01 & 0.02 & $\underline{0.86}^{* * * *}$ & -0.14 & -0.06 & 0.00 & -0.01 & -0.01 & 0.00 & 0.64 \\
\hline GM & 0.00 & 0.00 & -0.01 & 0.01 & 0.61 & $\underline{-0.26}^{* * * *}$ & -0.03 & 0.03 & -0.04 & -0.01 & 0.00 & 0.31 \\
\hline EPP & 0.00 & 0.00 & 0.00 & 0.04 & 0.67 & -0.07 & $\underline{-0.10}$ & 0.04 & -0.05 & -0.01 & 0.00 & 0.52 \\
\hline DA & 0.00 & 0.01 & -0.01 & 0.02 & 0.03 & -0.08 & -0.03 & $\underline{0.12}$ & -0.13 & -0.02 & 0.00 & -0.08 \\
\hline DS & 0.00 & 0.01 & -0.01 & 0.02 & 0.08 & -0.08 & -0.04 & 0.12 & $\underline{-0.13}$ & -0.02 & 0.00 & -0.05 \\
\hline SL & 0.00 & 0.00 & 0.01 & 0.01 & 0.23 & -0.06 & -0.03 & 0.04 & -0.05 & $\underline{-0.05}$ & 0.00 & 0.11 \\
\hline $\mathrm{TL}$ & 0.00 & 0.00 & 0.00 & 0.01 & 0.17 & 0.04 & -0.01 & 0.02 & -0.02 & 0.01 & $\underline{-0.02}$ & 0.19 \\
\hline
\end{tabular}

PH: Plant height, EH: ear height, NP: number of plants, NE: number of ears, EW: ear weight, GM: grain moisture, EPP: ear prolificacy, DA: days to anthesis, DS: days to silking, SL: stem lodging, TL: tillering.

${ }_{* * *}^{*}$ Significant at 0.001 probability level. 
resulted in clustering the inbred lines into 10 groups (Reid et al., 2011). Similar results were reported by Wen et al. (2011) where nine main subsets were clustered using pedigree information.

\section{Correlation among phenotypic traits}

There was significant correlation among phenotypic traits. Grain yield exhibited negative correlation with plant height and ear height though for ear height it was significant $(\mathrm{p}<$ 0.05). These results are in line with Sreckov et al. (2011) but in contrast with Bocanski et al. (2009). This means that these genes were lacking in the parents of the hybrids, hence negative correlation. This also means that shorter hybrids gave high yields. Grain yield showed highly significant $(\mathrm{p}<$ 0.01 ) negative association with days to anthesis and days to silking. These results showed that breeding for earliness has a potential of increasing yield unlike selection for flowering. This also implies that this trait is less influenced by the environment, hence it is more influenced by genetic factors and thus it is more heritable which makes it a suitable trait when selecting for grain yield indirectly. These results are consistent with Pavan et al. (2011), who observed a negative correlation between grain yield and days to $50 \%$ silking but in contrast with Selvaraj and Nagarajan (2011) who reported that anthesis date and silking date showed positive nonsignificant association with grain yield.

The negative correlation between yield and days to silking is very important to the breeder to identify early and late maturing cultivars. It means that yield is compromised when silk emergence is delayed. Grain yield showed highly significant $(p<0.01)$ and negative association with stem lodging. This means that if the plant is lodged its ability to transmit nutrients to the rest of the plant is reduced. This may be attributed to environmental factors such as heavy rains coinciding with wind or management factors such as high plant densities. It can also be due to the fact that the stems were more prone to pest and diseases hence stem lodging occurred.

\section{Path analysis}

Partitioning yield components into direct and indirect effects is of importance to the breeder so that traits that directly contribute to yield are selected. The results show that ear weight had the highest significant direct effect on grain yield. Therefore, grain yield can be improved by selecting for ear weight. In this study, stem lodging had positive and significant correlation with grain yield, but when it was further partitioned using path analysis it had negative direct effects on grain yield meaning that direct selection for this trait can compromise yield of hybrids. Direct negative effects that were attributed to days to silking indicate that selection for late silk emergence results in less grain yield. This is in concurrence with earlier reports by Raghu et al. (2011). Ear weight had the highest direct and positive effects on grain yield, which is in line with Ilker (2011), who reported that maximum positive contribution of fresh grain yield was through ear weight. This indicates that this trait could be used more confidently as the selection criteria in the grain yield improvement of maize hybrids. Plant height had no contribution to yield which is contrary to previous studies by Hepziba et al. (2013) that have reported that grain yield had direct and positive effects with plant height.

The indirect effects were categorized into three groups where number of plants, stem lodging and tillering had negligible indirect effects on grain yield. Days to silking and ear prolificacy had low indirect effects and only grain moisture had moderate indirect effects on grain yield.

\section{CONCLUSIONS}

There is large genetic diversity among widely grown maize hybrid brands in Southern Africa. There is however very little diversity within the brands suggesting that narrow genetic based populations have been used to derive the inbred parents for the hybrids. Both molecular and phenotypic data were effective for discriminating the hybrids into different clusters according to genetic background. SNP markers showed that there are nine clusters of hybrids. Positive significant direct effects of ear weight on grain yield can be attributed to greater photosynthate, which could have accumulated in each grain hence giving higher ear diameter. Consequently, this could be part of a good selection index for high yielding maize hybrids. Indirect effects played a minor role on determining yield potential of the hybrids.

\section{ACKNOWLEDGEMENTS}

We acknowledge support by the Generation Challenge Program (GCP), Alliance for a Green Revolution in Agriculture (AGRA) and National Research Fund (NRF) for funding the maize research projects. We are grateful to KwaZulu-Natal Department of Agriculture and Rural Development (South Africa) for providing access to land and use of research facilities at Cedara and Ukulinga Research Stations.

\section{REFERENCES}

Bertan, I., F. Carvalho, and A.C.D. Oliveira. 2007. Parental selection strategies in plant breeding programs. Journal of Crop Science and Biotechnology 10:211-222.

Bocanski, J., Z. Sreckov, and A. Nastasic. 2009. Genetic and phenotypic relationship between grain yield and components of grain yield of maize (Zea mays L.) Genetika 41:145-154.

Botstein, D., R.L. White, M. Skolnick, and R.W Davis. 1980. Construction of a genetic linkage map in man using RFLP. American Journal of Human Genetics 32:314-324.

Cheres, M., J. Miller, J. Crane, and S. Knapp. 2000. Genetic distance as a predictor of heterosis and hybrid performance within and between heterotic groups in sunflower. Theoretical and Applied Genetics 100:889-894.

Cholastova, T., M. Soldanova, and R. Pokorny. 2011. RAPD and SSR marker efficacy for maize hybrid identification. African Journal of Biotechnology 10:4794-4801. 
Choukan, R. 2011. Genotype $\times$ Environment interaction effects on the performance of maize (Zea mays L.) inbred lines. Crop Breeding Journal 2:97-103.

Dandolin, T.S., C.A Scapim, A.T. Amaral Junior, C.A Manngolin, M.F. Machado, A.S Mott, et al. 2008. Genetic divergence in popcorn lines detected by microsatellite markers. Crop Breeding and Applied Biotechnology 8:313-320.

Foster, J.T., G.J. Allan, A.P. Chan, P.D. Rabinowicz, J. Ravel, P.J. Jackson, et al. 2010. SNPs for assessing genetic diversity in castor bean (Ricinus communis). BMC Plant Biology 10:13-19.

Hallauer, A.R., and J. Miranda. 1988. Quantitative genetics in maize breeding. Iowa State University Press, Ames, Iowa, USA.

Hao, Z., X. Li, C. Xie, J. Weng, M. Li, D. Zhang, et al. 2011. Identification of functional genetic variations underlying drought tolerance in maize using SNP markers. Journal of Integrative Plant Biology 53:641-652.

Hasan, S.M.Z., M.S.B. Shafie, and R.M. Shah. 2008. Efficient method for the extraction of genomic DNA from wormwood (Artemisia capillaris). African Journal of Biotechnology 7:246-257.

Hepziba, S.J., K. Geetha, and S.M. Ibrahim. 2013. Evaluation of genetic diversity, variability, character association and path analysis in diverse inbreds of maize (Zea mays L.) Electronic Journal of Plant Breeding 4:1067-1072.

Ilker, E. 2011. Correlation and path coefficient analyses in sweet corn. Turkish Journal of Field Crops 16:105-107.

Karanja, J., N. Amugune, J. Ininda, J. Kimatu, and J. Danson. 2009. Microsatellite analysis of the correlation between molecular and morphological traits in assorted maize inbred lines. African Crop Science Journal 17:323-330.

Leal, A., C. Mangolin, A. Do Amaral Júnior, L. Gonçalves, C. Scapim, A. Mott, et al. 2010. Efficiency of RAPD versus SSR markers for determining genetic diversity among popcorn lines. Genetics and Molecular Research 9:9-18.

Liu, K., and S.V. Muse. 2005. PowerMarker: An integrated analysis environment for genetic marker analysis. Bioinformatics 21:2128-2129.

Lu, Y., T. Shah, Z. Hao, S. Taba, S. Zhang, S. Gao, et al. 2011. Comparative SNP and haplotype analysis reveals a higher genetic diversity and rapider LD decay in tropical than temperate germplasm in maize. PloS ONE 6:24861.

Lu, Y., J. Yan, C.T. Guimaraes, S. Taba, Z. Hao, S. Gao, et al. 2009. Molecular characterization of global maize breeding germplasm based on genome-wide SNP markers. Theoretical and Applied Genetics 120:93-115.

Magorokosho, C., B.S. Vivek, and J. Macrobert. 2009. Characterization of maize germplasm grown in Eastern and Southern Africa: Results of the 2008 Regional Trials Coordinated by Cimmyt. Harare, Zimbabwe.
Pavan, R., H. Lohithaswa, M. Wali, G. Prakash, and B Shekara. 2011. Correlation and path coefficient analysis of grain yield and yield contributing traits in single cross hybrids of maize (Zea mays L.) Electronic Journal of Plant Breeding 2:253-257.

Raghu, B., J. Suresh, S.S. Kumar, and P. Saidaiah. 2011. Character association and path analysis in maize (Zea mays L.) Madras Agricultural Journal 98:7-9.

Reid, L.M., K. Xiang, X. Zhu, B.R. Baum, and S.J. Molnar. 2011. Genetic diversity analysis of 119 Canadian maize inbred lines based on pedigree and SSR markers. Canadian Journal of Plant Science 91:651-661.

SAS Institute. 2011. Statistical Analysis Software/Stat Software, Version 9.3. $2^{\text {nd }}$ ed. SAS Institute, Cary, North Carolina, USA.

Schaefer, C.M., and R. Bernardo. 2013. Population structure and SNP diversity of historical Minnesota maize inbreds. Crop Science 53:1529-1536.

Scott, R., and G. Milliken. 1993. A Statistical Analysis Software (SAS) Program for analyzing augmented randomized completeblock designs. Crop Science 33:865-867.

Selvaraj, C., and P. Nagarajan. 2011. Interrelationship and pathcoefficient studies for qualitative traits, grain yield and other yield attributes among maize (Zea mays L.) Journal of Plant Breeding and Genetics 10:56-63.

Semagn, K., C. Magorokosho, B.S. Vivek, D. Makumbi, Y. Beyene, S. Mugo, et al. 2012. Molecular characterization of diverse CIMMYT maize inbred lines from Eastern and Southern Africa using SNP markers. BMC Genomics 13:113-121.

Shahrokhi, M., and S. Khavarikhorasani. 2013. Study of morphological traits, yield and yield components on 28 commercial corn hybrids (Zea mays L.) International Journal of Agronomy and Plant Production 4:2649-2655.

Sreckov, Z., A. Nastasic, J. Bocanski, I. Djalovic, M. Vukosavlje, and B. Jockovic. 2011. Correlation and path analysis of grain yield and morphological traits in test-cross populations of maize. Pakistan Journal of Botany 43:1729-1731.

Wen, W., J.L. Araus, S. Trushar, J. Cairns, J.G. Mahuku, M. Bänziger, et al. 2011. Molecular characterization of a diverse maize inbred line collection and its potential utilization for stress tolerance improvement. Crop Science 51:2569-2581.

Yan, J., X. Yang, T. Shah, H. Sánchez-Villeda, J. Li, M. Warburton, et al.2010. High-throughput SNP genotyping with the Goldengate Assay in maize. Molecular Breeding 2:441-451.

Yang, X., Y. Xu, T. Shah, H. Li, Z. Han, J. Li, et al. 2011. Comparison of SSR markers and SNP markers in assessment of genetic relatedness in maize. Genetica 139:1045-1054. 